\title{
CONFLITO NO AMBIENTE ESCOLAR E O CUIDADO DE SI EM MICHEL FOUCAULT
}

\author{
CONFLICT IN THE SCHOOL ENVIRONMENT AND CARE OF THE SELF IN \\ MICHEL FOUCAULT
}

\author{
Samuel Mendonça \\ Doutorado \\ Pontifícia Universidade Católica de Campinas - PUC Campinas/CNPq \\ Campinas, São Paulo - Brasil \\ samuelms@gmail.com \\ Kelly Cristina Leandro \\ Licenciatura \\ Pontifícia Universidade Católica de Campinas - PUC Campinas \\ Paulínia, São Paulo - Brasil \\ kelly1808@outlook.com
}

\begin{abstract}
Resumo: O conceito de cuidado de si de Michel Foucault, extraído do livro A Hermenêutica do Sujeito, caracteriza-se como caminho necessário para a construção da existência humana, ao demonstrar a necessidade de voltar-se a si mesmo. Desse modo, a realidade de conflitos existente na escola expressase como potência para a transformação das pessoas. Em vista disso, o presente artigo tem como pergunta: o conceito de cuidado de si de Michel Foucault pode auxiliar na resolução de conflitos em sala de aula? A metodologia utilizada reside em pesquisa bibliográfica, que se configurou em revisão de literatura e exame minucioso do livro do pensador francês. De forma sistemática, obteve-se como resultados: (i) a possibilidade de auxílio do conceito de cuidado de si como busca de retorno a si; (ii) o uso do cuidado de si como elemento de transformação da subjetividade na conquista individual; e (iii) a construção de abertura de postura para que se possa lidar com conflitos.
\end{abstract}

Palavras-chave: cuidado de si; conflito; escola; Michel Foucault.

Abstract: The concept of care of the self by Michel Foucault, extracted from the book entitled "The Hermeneutics of the Subject", characterizes itself as the required path for the human existence construction, upon demonstrating the necessity to the return to the self. Thus, the existing reality of conflicts at school expresses the power for people transformations. In view of that, the present article poses the question: can the concept of care of the self by Michel Foucault aid to resolve conflicts in the classroom? The utilized methodology lies in bibliographic research, comprised of a literature review and a meticulous inspection of the French thinker's book. The following results were systematically observed: (i) the care of the self-concept as a possible aid to the quest for the return to the self; (ii) the care of the self-employed as a transforming element of the subjectivity in the individual conquest and (iii) the construction of an open posture in order to deal with conflicts.

Keywords: care of the self; conflict; school; Michel Foucault.

Para citar - (ABNT NBR 6023:2018)

MENDONÇA, Samuel; LEANDRO, Kelly Cristina. Conflito no ambiente escolar e o cuidado de si em Michel Foucault. Eccos - Revista Científica, São Paulo, n. 57, p. 1-18, e11349, abr./jun. 2021. Disponível em: https://doi.org/10.5585/eccos.n57.11349. 


\section{Introdução}

O pensamento de Michel Foucault tem sido utilizado como fonte para estudos em diferentes áreas, com destaque para a filosofia (CANDIOTTO, 2007, 2008; FURTADO, 2015), a psicanálise (SILVA, 2001; CHECCHIA, 2010) e a saúde (CIRINO, 2007; CAPONI, 2007). No campo educacional, investigações têm sido realizadas colocando em relevo o tema da formação de professores (ALVES, 2017), de currículo (AQUINO, 2014; SCHERTNER, ROVEDA e LOPES, 2016), de inclusão (PAGNI, 2015), entre outros.

Este artigo discute a questão do conflito entre estudantes, utilizando-se de algumas pesquisas empíricas, como as realizadas por Chrispino (2007), Paiva e Lourenço (2011) e Castro (2016), e colocando em relevo o cuidado de si de Michel Foucault (2011) como conceito potente para a resolução dos referidos conflitos. Trata-se, portanto, de pesquisa teórica que considera achados de pesquisas empíricas sobre o tema. De pronto, assume-se que não houve exame do conceito de cuidado de si presente em História da Sexualidade 3 (1985).

Se for possível pensar com Foucault (2011) sobre o tema de conflitos em sala de aula, envolvendo, por certo, a questão da disciplina, do ponto de vista metodológico seria viável empreender tal esforço a partir de diferentes matrizes, como as relações de poder (FOUCAULT, 1979) ou mesmo a análise de discurso (FOUCAULT, 2009). No entanto, o artigo assume o curso "A Hermenêutica do Sujeito", ministrado por Foucault em 1981 e 1982 no Collège de France como base, seja por evidenciar o conceito de cuidado de si como chave de compreensão do sujeito, seja, principalmente, por reconhecer que as relações entre pares, neste caso, entre estudantes, podem ser equacionadas acompanhando a referência teórica de um autor que se preocupou com formas de existência que possam significar uma vida fecunda e genuína porquanto vivida por cada um, assumida por cada um. Talvez se possa, efetivamente, resolver conflitos no ambiente escolar justamente quando os estudantes estiverem aptos ao conhecimento de si por meio do cuidado de si.

Marcello e Fischer (2014) foram enfáticos em demonstrar a correlação de Foucault (2011) com o tema da verdade e, fundamentalmente, com o cuidado de si. Acreditar na possibilidade de uso do texto de Foucault (2011) como chave para conhecer e resolver problemas, eis o propósito deste artigo que assume natureza atípica, mas, justamente, ousada por considerar o pensamento de Michel Foucault.

Do ponto formal, apresenta-se um panorama geral a respeito do conceito de cuidado de si em Michel Foucault (2011), sistematizado na obra A Hermenêutica do Sujeito, enfatizando os pontos centrais que fundamentam tal compreensão. Em seguida, com o intuito de apresentar 
o contexto de conflito que se estabelece nas relações em sala de aula, serão discutidos os fatores que constituem tal realidade, a partir de Chrispino (2007), Paiva e Lourenço (2011) e Castro (2016). Por fim, a partir da sistematização do conceito de cuidado de si em Michel Foucault (2011) e da análise dos três estudos empíricos que tratam do conflito em sala de aula, algumas reflexões a respeito da possibilidade de articulação do referido conceito com a resolução de conflitos em sala de aula serão realizadas na forma de resultados alcançados.

\section{Cuidado de si em Foucault}

A sistematização do conceito de cuidado de si define-se como elemento central do presente artigo. Desse modo, este primeiro item apresenta, precisamente, a emergência do conceito de cuidado de si no debate filosófico, por meio da fundamentação apresentada no livro A Hermenêutica do Sujeito, de Michel Foucault (2011). Busca-se, portanto, delinear os pontos centrais que constituem a compreensão acerca do cuidado de si, para responder à pergunta: em que consiste o conceito de cuidado de si em Michel Foucault (2011)?

A trajetória reflexiva percorrida pelo referido autor, em suma, centra-se no estudo do sujeito e na busca por compreendê-lo em seus múltiplos sentidos, aspirando desvendar os jogos de verdade que são por ele criados e experienciados. Para isso, o estabelecimento de análises que traçam a genealogia histórica de temáticas relacionadas ao saber, ao poder e à sexualidade como fatores constitutivos da experiência do indivíduo caracteriza as motivações de estudo do autor.

Indicado, assim, de modo breve, o lugar em que Foucault (2011) tece suas análises e seus anseios de apreensão do que constitui o ser externa e internamente, avancemos ao centro do que se pretende analisar. Assumindo que as formulações construídas pelo autor caracterizam-se pela compreensão do sujeito enquanto protagonista situado em campos discursivos e de pensamento, responsáveis por orientá-lo a existir de determinada forma, compreende-se que o conceito de cuidado de si coloca-se como um caminho reflexivo que permite o vislumbre da possibilidade de construção de relações tão transformadoras consigo mesmo, que as interações vivenciadas no âmbito social poderão ser um reflexo do que é vivido em si.

Apreender o conceito de cuidado de si em dimensões que permitam uma compreensão que toque uma parte do todo que o imperativo de cuidar de si significa, requer uma análise cuidadosa, pois aspectos importantes circundam as origens de tal noção. Desse modo, o cuidado de si, em Michel Foucault (2011), é discutido pelo autor a partir de uma perspectiva histórica, 
com um olhar preciso para a influência desse conceito nos modos de subjetividade do sujeito histórico.

Epiméleia heautoû, termo grego que designa o "cuidado de si mesmo", de acordo com Foucault (2011), orientou por longo tempo a questão do sujeito e o relacionamento consigo mesmo na civilização grega. A escolha do autor por esse termo para discutir a subjetividade, em suma, as relações entre sujeito e verdade ao longo da história, firma-se na observação de que o preceito gnôthi seautón, "conhece-te a ti mesmo", ganhou grande protagonismo no debate filosófico em detrimento do conceito de epiméleia heautoû.

De acordo com o filósofo francês, o imperativo de conhecer a si mesmo aparece em muitos momentos associado ao princípio de cuidar de si. E tal associação foi se constituindo de forma tão íntima, que pouco a pouco o preceito gnôthi seautón foi se sobrepondo ao epiméleia heautô̂, de maneira que o cuidado de si pode ser entendido como a base que fundamenta e justifica o conhecer a si mesmo.

Na perspectiva de Foucault (2011), a principal figura associada ao imperativo "conhecete a ti mesmo" é a de Sócrates, de maneira que a ele é atribuída a incumbência de ser o portavoz dos deuses para incitar os outros a se ocuparem consigo mesmos. Em relação a isso, Foucault (2011) ressalta alguns pontos que podem ser analisados em uma passagem da obra Apologia de Sócrates, em que Sócrates (apud, FOUCAULT, 2011) coloca-se como responsável por incitar a todos que cruzam o seu caminho. Destaca-se o ponto em que o chamamento feito por Sócrates se configura como o papel daquele que desperta, em que:

[...] o cuidado de si é uma espécie de aguilhão que deve ser implantado na carne dos homens, cravado na sua existência, e constitui um princípio de agitação, um princípio de movimento, um princípio de permanente inquietude no curso da existência. (FOUCAULT, 2011, p. 9).

Para além de uma atitude que se assume consigo mesmo, a noção de epiméleia heautoû, de acordo com o referido autor, firmou-se como um princípio fundamental na atitude filosófica na cultura grega, romana e helenística, assim como na espiritualidade cristã. Mais do que um chamamento, o cuidado de si tornou-se um fenômeno cultural, do pensamento, que ganhou profunda expressividade nos modos de subjetividade do sujeito.

Para o filósofo de A Hermenêutica do Sujeito, cuidar de si pode ser entendido como um modo de existir e relacionar-se consigo mesmo de forma permanente e constante, estando o sujeito atento ao seu interior e se colocando em contínuo movimento e agitação que o direciona sempre a novos níveis de apreensão de sua interioridade. Desse modo, para compreender de 
forma concreta as dimensões que a epiméleia heautoû possui, três elementos são citados por Foucault (2011).

Em primeiro lugar, o cuidado de si deve ser visto como uma atitude que se assume para consigo, para com o mundo e para com as pessoas, como uma forma com a qual se escolhe estar no mundo. Em segundo lugar, o cuidado de si (epiméleia heautoû) implica uma conversão do olhar, de modo que haja um movimento de retorno para o que se passa dentro de si, dentro do próprio pensamento. E, por último, a noção de epiméleia heautô̂ não é só um posicionamento que se assume mentalmente, mas uma série de técnicas e atitudes concretas que devem ser praticadas para que de fato se atinja, em longo prazo, a transformação e até mesmo a purificação de si. Foucault (2011) afirmou que:

Enfim, com a noção de epiméleia heautoû, temos todo um corpus definindo uma maneira de ser, uma atitude, formas de reflexão, práticas que constituem uma espécie de fenômeno extremamente importante, não somente na história das representações, nem somente na história das noções ou das teorias, mas na própria história da subjetividade ou, se quisermos, na história das práticas da subjetividade. (FOUCAULT, 2011, p. 12).

Traçado o panorama geral da problemática do cuidado de si, o texto de Alcibíades (apud. FOUCAULT, 2011), rememorado por Foucault (2011), coloca-se como elemento central de ser retomado, mesmo que de forma breve, para gerar o aprofundamento necessário em alguns aspectos centrais que originalmente fundamentam a emergência da noção de epiméleia heautoû.

Nesse diálogo, na interpretação de Foucault (2011), ao deparar-se com um jovem homem, bem abastado e de boa aparência, Sócrates enxerga nele um desejo por mais, que desperta seu interesse. Alcibíades coloca-se como alguém que busca não somente usufruir de seus privilégios e conquistar o governo da cidade, situação que é esperada devido ao seu status e origem aristocrática, mas também como alguém que carrega dentro de si uma vontade de ir além, de voltar-se para o governo dos outros. Alcibíades, portanto, deseja “[...] transformar o privilégio de status, a primazia estatutária em governo dos outros” (FOUCAULT, 2011, p. 32).

De acordo com o filósofo francês, é neste momento que a questão do cuidado de si surge. Ao enxergar a motivação de Alcibíades em governar os outros, Sócrates identifica algumas ineficiências em sua condição, e assim diz a ele que, para ultrapassar a condição de privilégio estatutário e assumir o governo da cidade, é necessário que se ocupe de si mesmo, que cuide de si. Cuidar de si, portanto, surge como uma exigência prévia para a ação política, como uma medida de reparo ao déficit pedagógico e, ainda, como uma prática que deve ser desenvolvida enquanto ainda se é jovem. 
Para Foucault (2011), após Alcibíades expressar seu ímpeto por governar os outros, duas questões se colocam quando ele percebe que ignora a si mesmo. Ao notar que ignora e que é preciso ocupar-se consigo, surge o questionamento sobre “o que é 'si mesmo' e o que é ‘ocuparse"” (FOUCAULT, 2011, p. 44). Desse modo, para atingir de forma relevante as transformações que o cuidado de si pode provocar, é necessário que Alcibíades compreenda esses dois elementos que compõem o movimento de retorno a si.

A respeito do primeiro questionamento, chega-se à conclusão de que o "eu" que deve ser o alvo do ato de ocupação é a alma, ou seja, o sujeito é seu próprio objeto, e seu objeto de cuidado encontra-se nele mesmo, qual seja, a alma. Nesse sentido, a alma é vista enquanto sujeito de ação, que ao ter essa característica deve ser tratada com atenção e rigor. Com relação à segunda questão, de acordo com a análise do diálogo socrático apresentada por Foucault, chega-se à afirmação de que ocupar-se consigo deve consistir em conhecer-se a si mesmo. Nesse ponto, considera-se interessante observar o movimento criado entre as noções de cuidar de si e conhecer a si mesmo, ou seja, como a relação entre epiméleia heautoû e gnôthi seautón e vai sendo construída. Com o entendimento de que o cuidado de si deve acontecer por meio do conhecimento de si, o preceito de cuidado de si (epiméleia heautô̂) passará a ser, gradualmente, subjugado pela noção de conhecer a si mesmo (gnôthi seautón).

Ao ser esclarecido por Foucault (2011) que o eu com que se deve ocupar é a alma, e que tal ocupação consiste no conhecimento de si, outro elemento relacionado ao conceito de cuidado de si é a noção de voltar-se ao divino. $\mathrm{O}$ ato de ocupar-se com a alma para alcançar o conhecimento de si consiste em olhar para algo que ao ser da mesma natureza que se é, por meio do pensamento e do saber, produz o resultado de encontro com a essência da sabedoria.

Em sua complexidade, o cuidado de si revela-se na corrente de pensamento platônica, de acordo com Foucault (2011), como um estado de constante busca por mais de si, por conhecer mais sobre o eu, percorrendo caminhos que se direcionam ao acesso à essência da sabedoria, como forma de viver consciente daquilo que a vida pode colocar diante de nós.

Pode-se observar nas práticas filosóficas ou espirituais, como aponta Foucault (2011), um caráter positivo no modo de vida, na estruturação moral que o cuidado de si oferece. Tal compreensão era própria do pensamento antigo ${ }^{1}$, de modo que na antiguidade "ocupar-se consigo mesmo" nunca indicava um ato negativo, mas sempre positivo além de se fundamentar em atos profundamente rigorosos.

No entanto, assumir o entendimento de "prestar culto a si", "voltar-se sobre si mesmo", “sentir prazer em si mesmo" (FOUCAULT, 2011, p. 13) coloca-se, na atualidade de nosso pensamento, como algo um tanto egocêntrico na medida em que a coletividade é posta em 
segundo plano, como se o ato de cuidar de si fosse a única alternativa restante para quem não consegue incorporar em seus atos a moral coletiva.

Outro ponto de destaque ressaltado por Foucault (2011), para a compreensão das possíveis razões segundo as quais o preceito de "cuidado de si" foi preterido pela noção de "conhece-te a ti mesmo", consiste propriamente nos impactos trazidos pelo chamado "momento cartesiano" (FOUCAULT, 2011, p. 18), que modificou consideravelmente as condições de acesso à verdade. Destaca-se, brevemente, que o citado "momento cartesiano" faz menção ao pensamento do filósofo René Descartes (1596-1650), que integrou de modo sistemático no debate filosófico a dimensão da racionalidade como forma essencial de acesso à verdade, por meio de um método com bases matemáticas que orienta o pensamento nesse caminho da verdade. Nas palavras de Foucault (2011, p. 171):

[...] a questão de nossa relação com a verdade, é a que, parece-me, desde Platão, desde esse Alcibíades iniciador, aos olhos da tradição platônica, de toda a filosofia, é assim colocada: a que preço posso ter acesso a verdade? [...] O sujeito enquanto tal, do modo como é dado a si mesmo, não é capaz de verdade [...] contudo, a não ser que efetue em si mesmo certas operações, certas transformações e modificações que o tornarão capaz de verdade.

Na sequência desse trecho, Foucault (2011, p. 171) argumenta ainda: “[...] minha ideia então é que, tomando Descartes como marco, evidentemente, porém sob o efeito de toda uma série de complexas transformações, é chegado um momento em que o sujeito como tal tornouse capaz de verdade". Portanto, se na antiguidade, segundo o autor de A Hermenêutica do Sujeito, para acessar a verdade o homem deveria operar transformações em seu ser, no momento em que passou a ser compreendido que o acesso à verdade acontece somente pelo conhecimento, que o sujeito é capaz de acessar a verdade da forma como é, as transformações postuladas pela espiritualidade e em certa medida pela noção de cuidado de si foram desaparecendo.

Compreende-se, portanto, que as condições de acesso à verdade transformaram-se em procedimentos metodológicos muito distantes dos característicos da espiritualidade. Se para obter o acesso à verdade, na perspectiva da espiritualidade, o ser do sujeito deve sofrer transformações que lhe criem condições propícias para atingir tal objetivo, com a forma moderna de concepção de acesso à verdade, um conjunto de regras, um método rigoroso assume a posição de preparador do ser do sujeito.

Vale ressaltar que a reformulação das formas de acesso à verdade, em que o cuidado de si foi sendo negligenciado, não ocorreu abruptamente, mas por meio de um processo gradual de reestruturação das práticas de cuidado de si. Em Alcibíades, ainda na interpretação de 
Foucault (2011), ocorre toda uma reorganização progressiva das antigas noções e práticas de si. Antigas tecnologias do eu já existiam, como, por exemplo, nos pitagóricos, que tinham práticas voltadas para o cuidado com o eu, técnicas de concentração, de purificação, de provação etc. A respeito disso, Foucault (2011, p. 63) observa que:

[...] de fato, recuperando e reintegrando algumas daquelas técnicas anteriores, arcaicas, preexistentes, todo o movimento do pensamento platônico a propósito do cuidado de si consistiria, precisamente, em dispô-las e subordiná-las ao grande princípio do "conhece-te a ti mesmo". É para conhecer-se a si mesmo que é preciso dobrar-se sobre si; é para conhecer-se a si mesmo que é preciso desligar-se das sensações que nos iludem; é para conhecer-se a si mesmo que é preciso estabelecer a alma em uma fixidez imóvel que a desvincula de todos os acontecimentos exteriores.

Expandindo, ainda, para um dos últimos escritos de Foucault (1985), precisamente ao terceiro volume da História da sexualidade, podemos observar, em um dos capítulos, a descrição do método de Artemidoro de análise dos sonhos, que expressa de modo claro uma modalidade das práticas de si que se coloca muito próxima à realidade das pessoas comuns.

Decifrar os sonhos e seus possíveis significados fazia parte das técnicas de existência fundamentais na antiguidade. Fragmentos da realidade e do futuro estão contidos nas imagens projetadas nos sonhos e, desse modo, analisá-las proporciona a interpretação dos significados de tais representações e como elas se conectam com a vida do sujeito.

Nessa perspectiva, a metodologia de análise dos sonhos proposta por Artemidoro, na análise de Foucault (2011), não se voltava para o julgamento moral daquilo que era expresso na mente durante o repouso. Em realidade, essa metodologia expressava o modo como as representações se relacionam com a realidade do sujeito e, além disso, como essas experiências vividas nos sonhos podem interferir na condução das ações pelo sujeito.

Em suma, a vontade de elaborar conceitos, verdades construídas como irrevogáveis, foi sendo viabilizada pelo homem por meio da prerrogativa de munir-se de práticas, sejam elas espirituais ou metodológicas, que tragam a garantia necessária para buscar a verdade de forma coerente.

No transcorrer da história, os preceitos de acesso à verdade foram modificados e orientados em direções cada vez mais diversas. O cuidado de si, por exemplo, que estava inserido nesse movimento de práticas que asseguram a busca pela verdade, deu origem a toda a lógica de subjetividade envolvida nesse processo.

As relações entre sujeito e verdade foram sendo intermediadas por noções e práticas que gradualmente foram distanciando-se da dimensão espiritual e aproximando-se de uma perspectiva cada vez mais externa à espiritualidade do indivíduo e mais próxima da cientificidade alheia. Com isso, proporcionaram a construção da subjetividade do indivíduo, de 
seu modo de ser, sentir e existir social e historicamente. Passa-se à análise de conflitos em sala de aula.

\section{Conflito em sala de aula}

Considerando a necessidade de realização de pesquisa empírica a fim de que se tenham informações precisas sobre a questão de conflitos em sala de aula, este item apresenta a sistematização de três pesquisas, quais sejam, de Chrispino (2007), de Paiva e Lourenço (2011) e de Castro (2016). A partir delas e considerando o item anterior, sobre o conceito de cuidado de si, busca-se responder à pergunta do artigo: o conceito de cuidado de si de Michel Foucault pode auxiliar na resolução de conflitos em sala de aula?

No estudo realizado por Chrispino (2007, p. 13) são apresentados os resultados de uma pesquisa realizada pelo IBOPE, intitulada "O jovem, a sociedade e a ética", que identificou nos alunos a compreensão do valor que a educação possui em sua formação, assim como a expressão de sua preocupação com a violência presente na escola. Cerca de $50 \%$ dos jovens entre 14 e 18 anos que foram entrevistados consideram a escola como a segunda maior responsável pela garantia de um bom futuro. No que se refere à questão da violência, $60 \%$ dos entrevistados afirmaram que esse é o maior problema que o Brasil enfrenta atualmente.

Ao compreender, por meio dos dados apresentados pelo IBOPE, que os alunos confiam na educação e que identificam na violência um grande problema enfrentado pela sociedade, o autor tece algumas considerações que visam compreender as causas que geram a violência escolar. Desse modo, o conflito é definido por Chrispino (2007, p. 15) como "[...] toda opinião divergente ou maneira diferente de ver ou interpretar algum acontecimento". Ainda, o autor ressalta que:

[...] todos os que vivemos em sociedade temos a experiência do conflito. Desde os conflitos próprios da infância, passamos pelos conflitos pessoais da adolescência e, hoje, visitados pela maturidade, continuamos a conviver com o conflito intrapessoal (ir/não ir, fazer/não fazer, falar/não falar, comprar/não comprar, vender/não vender, casar/não casar etc.) ou interpessoal [...]. (CHRISPINO, 2007, p. 15).

Situando o conflito como elemento presente nas relações que o indivíduo estabelece consigo mesmo e com o outro, os conflitos educacionais são definidos pelo autor como aqueles que se manifestam no ambiente próprio às práticas escolares, por meio das relações estabelecidas por seus atores. Assim, a mediação de conflito é apresentada como procedimento importante para a resolução de conflitos, pois ela "[...] pode induzir a uma reorientação das 
relações sociais, a novas formas de cooperação, de confiança e de solidariedade" (CHRISPINO, 2007, p. 23).

Por sua vez, no estudo empírico realizado por Paiva e Lourenço (2011), o conflito é discutido por outra perspectiva, em que se analisa um aspecto referente à personalidade, precisamente a conscienciosidade, assim como as variáveis demográficas sexo, idade e ano de escolaridade, na busca por determinar a relevância desses elementos na eficácia negocial. Desse modo, de acordo com os autores, o conflito pode ser entendido como "[...] um poderoso antídoto contra a estagnação, podendo estimular o interesse e a curiosidade e ser o meio mais credível para que os problemas possam ser esclarecidos, debatidos e discutidos" (PAIVA e LOURENÇO, 2011, p. 152).

O fator conscienciosidade, na perspectiva dos autores, é uma das facetas da personalidade que interferem nos processos negociais. Desse modo, é salientada a relevância de pensar esse elemento na eficácia negocial. Assim, a conscienciosidade “[...] avalia o grau de organização, perseverança e motivação no comportamento orientado para um determinado objetivo" (PAIVA e LOURENÇO, 2011, p. 153).

O método de negociação conflitual é assumido pelos autores como uma das melhores opções de resolver situações de conflito. Os resultados da pesquisa apontaram que alunas do sexo feminino, quando comparadas com os de sexo masculino, expressam uma facilidade maior em conduzir suas ações para resolver situações de conflito de forma criativa e dialógica, sendo mais conscienciosas. Ainda, alunos de anos de escolaridade posteriores possuem maiores habilidades na negociação conflitual. Nesse contexto, foi verificado por Paiva e Lourenço (2011) que os alunos mais conscienciosos, ou seja, aqueles que apresentam maior senso de realização, competência, organização, perseverança e motivação, são mais eficientes na negociação conflitual. A forma de resolução de conflitos é, portanto, possível, desde que sejam garantidas a interlocução e a tomada de posição dos sujeitos envolvidos.

O terceiro estudo empírico, realizado por Castro (2016), traz elementos referentes à perspectiva de estudantes de Pedagogia ao longo de sua formação, expressando seus conflitos pessoais e suas percepções acerca de sua subjetividade, do saber de si e dos outros, por meio dos registros realizados no formato diário de bordo, dentro de uma disciplina acadêmica que discute temas como sexualidade, relações de gênero e educação. Assim, “[...] ao dirigir a atenção para as práticas que pretendem formar docentes, é possível pensar nos modos como os sujeitos se produzem a partir delas e, assim, constituem subjetividades" (CASTRO, 2016, p. 40). 
A proposta de escrita da referida disciplina acadêmica é analisada por Castro (2011) na perspectiva de que o registro do processo de experiência possibilita aos estudantes visualizar o movimento de constituição de sua subjetividade, precisamente relacionada às temáticas gênero e sexualidade. A autora, portanto, assumindo uma perspectiva vinculada aos estudos foucaultianos e pós-estruturalistas, afirma que os “[...] sujeitos são constituídos por práticas discursivas e não discursivas, processo colocado em funcionamento num determinado contexto cultural e histórico" (CASTRO, 2016, p. 41).

De acordo com a autora, os relatos contidos nos diários de bordo das estudantes revelam sua subjetividade, e o próprio processo de escrever suas experiências possibilita enxergar aquilo que constitui seus pensamentos e suas opiniões, oportunizando a construção de novas ideias, modificando, produzindo e conhecendo a si mesmas. Assim, tendo Foucault (2009) como referência, Castro (2016, p. 52) afirma: “[...] aproprio-me da ideia da escrita produzida pelas estudantes nos diários de bordo como uma escrita experiência, que produz experiências, ao proporcionar que elas desgarrem de si”.

A partir das considerações contidas nos três estudos empíricos analisados, nota-se que não há consenso sobre o termo “conflito em sala de aula”. Mesmo assim, é possível argumentar que os conflitos existem e que uma forma de equacionamento diz respeito à conquista de espaço de interlocução e ao fortalecimento de cada sujeito de fala no sentido de garantir-lhes autonomia nas ações e, principalmente, na construção de seus enunciados. Enquanto Chrispino (2007) concebe o conflito na escola como um embate de ideias e posicionamentos, que pode ser solucionado por meio de ações comprometidas em diagnosticar as circunstâncias que geram o conflito para assim promover o diálogo, Paiva e Lourenço (2011), por sua vez, analisam-no como um elemento que pode ser resolvido por meio da negociação entre as partes envolvidas, ressaltando que indivíduos que possuem grau de conscienciosidade superior negociam seus conflitos de forma mais eficiente.

Assumindo, por fim, um ponto de vista específico sobre a realidade de formação de professores, Castro (2016), ao analisar a escrita de estudantes de Pedagogia, considera a escrita de si como uma prática que promove a produção da subjetividade, de modo que os pensamentos, as crenças e os valores possuídos podem ser constantemente revistos e reconstruídos, promovendo, portanto, o experienciar de si mesmo.

Tendo como referência os autores citados neste item, compreende-se que, independentemente do contexto, situações de conflito são vivenciadas com suas particularidades e intensidades, podendo ser vividas na interioridade do ser ou diariamente nas relações estabelecidas com as pessoas que nos cercam. Pensar, portanto, o conflito como 
elemento constituinte da vida em sociedade é imprescindível para compreendê-lo como um aliado no processo de formação do indivíduo, incorporando-o nas práticas pedagógicas com a naturalidade necessária para trabalhá-lo continuamente nas relações escolares.

Entende-se que os conflitos, quando não administrados em profundidade, como aponta Chrispino (2007), geram reflexos violentos que fragilizam, ainda mais, as relações que se estabelecem no meio escolar, de modo que um ambiente cada vez mais opressivo e degradante é identificado. Para além de moldar comportamentos, como aponta Paiva e Lourenço (2011), fazendo com que os estudantes tomem suas ações mais amenas somente para corresponder às expectativas e determinações da escola, é necessário propiciar a vivência do diálogo e a construção de um ambiente que acolha a diversidade de posicionamentos de seus atores, assim como de canais de escuta e aconselhamento.

Considera-se, ainda, que lidar e conviver com situações de conflito é um dos desafios que se impõem à realidade escolar, pois, ao considerar que a escola é um local diverso e detentor de múltiplas formas de interação, torna-se imprescindível buscar alternativas que possam colaborar na instauração de um ambiente provido de respeito, diálogo e crescimento pessoal e coletivo, possibilitando não só o desenvolvimento de um bom convívio interpessoal, mas também a construção de uma relação plena consigo mesmo.

Retomando a pergunta que o presente artigo busca responder - o conceito de cuidado de si de Michel Foucault pode auxiliar na resolução de conflitos em sala de aula? -, pode-se afirmar, com base nos estudos empíricos citados neste item, que o conceito de cuidado de si traz grandes possibilidades de auxílio na resolução de conflitos em sala de aula.

Compreende-se, por meio da sistematização acerca do conceito de cuidado de si em Michel Foucault (2011), que o ato de retornar a si, voltando-se para a interioridade do ser, do pensamento, enxergando sua própria subjetividade, seus modos de pensar, sentir e agir, para assim tecer ações, como a de escrita de si, analisada por Castro (2016), gera transformações na mentalidade dos atores escolares.

Desse modo, afirma-se que, ao compreender a importância de reconstituir-se continuamente de forma autêntica, desfazendo-se do pensamento rígido e estático, estando abertos a questionar seus próprios posicionamentos, visando estabelecer relações mais profundas consigo mesmos e com aqueles que os cercam, os sujeitos que compõem o ambiente escolar serão plenamente capazes de resolver seus conflitos de forma contínua e saudável, reduzindo os reflexos violentos da má gestão de conflito em sala de aula. Assume-se, portanto, que o conceito de cuidado de si firma-se como um auxiliador na resolução de conflitos em sala de aula. 


\section{Cuidado de si como possibilidade de resolução de conflitos}

Tendo como referência os itens anteriores, que discutiram o conceito de cuidado de si em Michel Foucault (2011) e a questão do conflito em sala de aula por meio da análise de três estudos empíricos que tratam dessa temática, esta seção apresenta a articulação do conceito de cuidado de si com a possibilidade de resolução de conflito em sala de aula.

Afirma-se que o cuidado de si se coloca como real possibilidade de auxílio na dissolução de conflitos, pois, ao ser experienciado pelo sujeito o movimento de retorno a si, as relações que se estabelecem externamente poderão ser modificadas, considerando que o sujeito estará orientado a direções existenciais mais profundas.

Compreende-se que Foucault (2011), em seus últimos escritos, evidencia a história do pensamento, da subjetividade empregada pelo homem nos seus mecanismos de pensar, indicando os principais saltos e transformações sofridos em cada momento histórico, assim como os modos de elaboração humana a respeito da experiência do sujeito consigo mesmo e no mundo.

O cuidado de si, nessa perspectiva, revela uma forma diferenciada de pensar ao retomar um modelo de experiência do pensamento até então esquecido, negligenciado. Tal modelo retoma a dimensão espiritual, da interioridade do sujeito, ao demonstrar que o retorno a si, por meio de práticas de análise e condução do pensamento e das ações, pode resultar na efetivação de uma relação transformadora consigo e com o mundo, a ponto de conferir novos significados à existência.

Pensando, portanto, no âmbito escolar, os conflitos vividos nesse espaço social revelam problemas que não podem ser tratados de modo superficial. Como indica Chrispino (2007), o emprego de medidas simplistas, além de agravar os reflexos violentos nas relações escolares, aprofunda a falta de diálogo e compreensão mútua da condição do outro. Desse modo, acreditase que tratar somente os sintomas e não as causas reais dos conflitos escolares não é suficiente para solucionar de modo efetivo e permanente as incompreensões estabelecidas nas relações em sala de aula.

Então, Foucault (2011), na interpretação de Berten (2011, p. 160), ao se “[...] interessar aos procedimentos 'internos', não mais exclusivamente aos efeitos sobre o indivíduo, mas interessando-se igualmente pelas relações do indivíduo consigo mesmo", oferece uma noção norteadora - e transformadora - dos modos pelos quais o sujeito pode conduzir a si mesmo. Nesse sentido, o pensador francês propõe, por meio da retomada da dimensão espiritual do 
indivíduo, uma forma de individualidade comprometida com a análise autossuficiente de si e dos modos de se relacionar com o outro.

A condução de si mesmo, demonstrada por Foucault (2011), exprime modos de gestão do pensamento e da própria conduta, por meio de exercícios que são desenvolvidos no interior de si e que são responsáveis por gerar formas de pensar e conduzir ações comprometidas em construir a existência com apreço e cuidado. Dessa maneira, revela-se que é possível moldar a existência de maneira efetiva ao munir-se de práticas que visam, como aponta Galvão (2014), construir a vida como uma obra de arte.

Ao demonstrar em suas análises, Foucault (2011) identifica "[...] a questão do vínculo entre o saber das coisas e o retorno de si [...]" (FOUCAULT, 2011, p. 206), nesse ponto, a conexão entre o saber - objeto presente na escola - e o retorno a si, elementos estes que, ao estarem articulados, são capazes de gerar transformações na interioridade do sujeito e, consequentemente, no modo de conduzir suas ações, que poderão refletir nas relações estabelecidas com o outro no ambiente escolar. Assim, compartilha-se da afirmação de Galvão (2014, p. 158), segundo a qual “[...] 'o cuidado de si' trata de um 'duplo-retorno', primeiramente um 'retorno a si' e, num segundo momento, um 'retorno para o outro e para o mundo' [...]”.

Quando Foucault (2011) analisa as escolas filosóficas cínicas, epicuristas e estoicas, também evidencia que o conhecimento do mundo e o retorno a si são elementos articulados, de modo que a separação dos saberes que tangenciam a existência humana daqueles que não o fazem oportuniza a apreensão do que realmente importa, sendo capaz de modificar o sujeito de maneira relevante e intencional. Dessa forma, revela-se que o conhecimento abre horizontes de reflexão passíveis de reorientar a percepção do sujeito com relação a si mesmo, ao mundo e à sua interação com o outro, contribuindo na resolução de conflitos.

Desse modo, pensando esses elementos no ambiente de sala de aula e considerando os conflitos que se estabelecem entre seus atores, afirma-se que orientar os saberes trabalhados na escola, visando não à sua transmissão vazia, mas sim à formação da percepção de mundo e dos modos de sentir, agir e pensar, pode ser um dos caminhos de incorporação do conceito de cuidado de si nas relações escolares.

Entende-se, ainda, que conhecer diferentes realidades, compreender a história de vida daqueles que partilham do contexto de sala de aula, colocando-se, gradualmente, no lugar do outro e experimentando os sentimentos e as vivências próprios da experiência que o outro carrega em si, pode contribuir para o estabelecimento de relações mais íntimas e significativas. Assim, a abertura à subjetividade do outro, além de oferecer a vivência da empatia e o aumento 
de repertório de experiências de vida possíveis, possibilita o contato com sua própria interioridade, contribuindo para a constituição autêntica de si.

Portanto, considera-se que evidenciar de modo prático que é possível conduzir a si mesmo, por meio da utilização de saberes que se relacionam com o contexto de vida do aluno, que o auxiliam a compreender e gerir seus medos, anseios e inquietações, de maneira que os conflitos instaurados em sala de aula sejam solucionados antes de adquirir feições violentas e repressoras, demonstra a real possibilidade de solucionar conflitos proporcionando o crescimento coletivo.

Por fim, à luz do conceito de cuidado de si em Michel Foucault (2011), conclui-se que é por meio deste chamado que se deve realocar a subjetividade em um novo lugar, que o cuidado de si apresenta a possibilidade de auxílio na resolução dos conflitos em sala de aula. $\mathrm{O}$ ato de retorno a si, no sentido de constituir-se a própria existência da melhor forma possível, eleva a subjetividade do sujeito a novos lugares, que, ao permitir acessar compreensões antes não experimentadas, oportuniza o estabelecimento de relações mais profundas e significativas com o outro.

\section{Considerações finais}

De acordo com o que foi apresentado nos itens anteriores - a sistematização do conceito de cuidado de si em Michel Foucault (2011), posteriormente a questão do conflito em sala de aula a partir da análise de três estudos empíricos e, por fim, a articulação desses dois aspectos -, os resultados alcançados confirmam a real possibilidade de resolução de conflitos em sala de aula por meio do conceito de cuidado de si em Michel Foucault (2011).

Ao retomar a pergunta que o presente artigo busca responder - o conceito de cuidado de si de Michel Foucault pode auxiliar na resolução de conflitos em sala de aula? -, afirma-se que o movimento de retorno a si, colocando a própria subjetividade como objeto de cuidado e atenção, transformando a percepção acerca de si e consequentemente sobre o outro, pode contribuir de forma efetiva na resolução de conflitos em sala de aula.

Como citado anteriormente, em Michel Foucault (2011) a noção de cuidado de si é investigada de maneira a elucidar que o ato de voltar a si mesmo, colocando sua interioridade como objeto de cuidado e tecendo a existência de modo consciente e intencional, é capaz de gerar a construção de uma relação plena consigo mesmo, com o mundo e com o outro.

No que se refere ao conflito em sala de aula, a partir da análise dos três estudos empíricos, compreende-se que a dimensão conflitual está presente nas relações escolares, no 
momento em que seus atores divergem quanto a ideias e posicionamentos. Desse modo, para que se instaure um ambiente de efetiva resolução de conflitos, é necessário o desempenho de ações comprometidas em impulsionar nos envolvidos o despertar para o conflito como um caminho de crescimento, que requer a participação de todos. É evidente que a resolução de conflitos a partir da matriz de Foucault significa lidar com relações de poder, com as contradições; no entanto, aqui se buscou demonstrar a possibilidade, por meio do esforço individual, de se conseguir a suficiente quietude que produz o conhecimento de si.

Ao articular os aspectos apresentados, ou seja, o conceito de cuidado de si no referido autor e a questão do conflito em sala de aula, na esteira da pergunta que o presente artigo propôs responder, afirma-se que a chave para a resolução de conflitos entre os atores escolares reside justamente nesses indivíduos. Essa é a conclusão mais impactante do artigo, isto é, o conceito de cuidado de si assume a dimensão da individualidade como chave para a resolução de conflitos no ambiente escolar.

A possibilidade de transformação do sujeito, potente no ambiente contraditório escolar, sobretudo mediante os conflitos, se dá na medida em que há o enfrentamento da condição existencial mais básica da vida, isto é, quando se volta a atenção para a natureza de cada um. Assim, é na dimensão subjetiva mais sublime que o epiméleia heautoû se concretiza.

Por derradeiro, mesmo que a investigação não tenha realizado pesquisa empírica, o fato de ter se apoiado em pesquisas empíricas já realizadas demonstra a potência de uso do cuidado de si de Foucault como base para a resolução de conflitos em sala de aula. Assim, sistematizamse os resultados alcançados em três perspectivas: (i) a possibilidade de auxílio do conceito de cuidado de si como busca de retorno a si, com ênfase na dimensão da individualidade; (ii) o uso do cuidado de si como elemento de transformação da subjetividade na conquista individual, e (iii) a construção de abertura de postura para que se possa lidar com conflitos, podendo ser tanto de professores ou estudantes.

O artigo não pretende esgotar o tema, por certo, no entanto, a continuidade desse estudo com pesquisa empírica poderá ser útil para a filosofia da educação na medida em que essa área do conhecimento tem estatuto próprio que não envolve, necessariamente, a dimensão científica de construção do conhecimento. Por fim, não se pode pensar a filosofia no geral, ou a filosofia da educação, de modo particular, sem olhar para a realidade concreta escolar. 


\section{Referências}

AQUINO, Julio Groppa. O pensamento como desordem: repercussões do legado foucaultiano. Pro-Posições, 2014, maio/ago, v. 25, n. 2 (74), p. 83-101.

BERTEN, André. Michel Foucault: Da disciplina à autodisciplina. In Modernidade e Desencantamento. Saraiva. São Paulo, 2011.

CANDIOTTO, Cesar. Governo e direção de consciência em Foucault. Natureza Humana, 2008, dez, vol.10, no.2, p. 89-113.

CANDIOTTO, Cesar. Verdade e diferença no pensamento de Michel Foucault. Kriterion, Belo Horizonte, 2007, n 115, Jun, p. 203-217.

CAPONI, Sandra. Michel Foucault e a persistência do poder psiquiátrico. Ciênc. Saúde Coletiva, Rio de Janeiro, 2009, Fev, v. 14, n. 1, p. 95-103.

CASTRO, Roney Polato de. Pensando sobre formação docente, subjetividade e experiência de si a partir da escrita de estudantes de Pedagogia. Pro-Posições, 2006, jan./abr, v. 27, n.1 (79), p. 37-55.

CHECCHIA, Marcelo A. A clínica psicanalítica é um dispositivo? A peste, São Paulo, 2010, jan/jun, v.2, n.1, p. 89-100.

CHRISPINO, Álvaro. Gestão do conflito escolar: da classificação dos conflitos aos modelos de mediação. Ensaio: aval. pol. públ. Educ., Rio de Janeiro, 2007, jan/mar., v.15, n.54, p. 1128.

CIRINO, Oscar. O desejo, os corpos e os prazeres em Michel Foucault. Mental, Barbacena, 2007, Jun, v. 5, n. 8, p. 77-89.

FOUCAULT, Michel. A Hermenêutica do Sujeito. 2. ed. São Paulo: Martins Fontes, 2011.

FOUCAULT, Michel. Arqueologia do saber. Rio de Janeiro: Forense Universitária, 2009.

FOUCAULT, Michel. História da Sexualidade 3. O cuidado de si. Trad. Maria Thereza da Costa Albuquerque. Rio de Janeiro: Graal, 1995.

FURTADO, Rafael Nogueira. A atualidade como questão: ontologia do presente em Michel Foucault. Natureza Humana, 2015, vol.17, no.1, p. 144-156.

FREITAS, Alexandre Simão de (2014). O cuidado de si e os perigos de uma ontologia ainda sem cabimento: o legado ético-espiritual de Foucault. Pro-posições, 2014, maio/ago, v. 25, n. 2 (74), p. 121-138.

GALVÃO, Bruno Abílio. A ética em Michel Foucault: do cuidado de si à estética da existência. Intuitio. Porto Alegre, 2014, vol. 7, no. 1, p. 157-168. 
MARCELLO, Fabiana de Amorim; FISCHER, Rosa Maria Bueno. Cuidar de si, dizer a verdade: arte, pensamento e ética do sujeito. Pro-Posições, Campinas, 2014, Ago, v. 25, n. 2 , p. $157-175$.

PAGNI, Pedro. Diferença, subjetivação e educação: um olhar outro sobre inclusão escolar. Pro-posições, 2015, jan/abr., v. 26, n. 1 (76), p. 87-103.

PAIVA, Maria Olímpia Almeida de; LOURENÇO, Abílio Afonso. Estudo empírico sobre a eficácia negocial de conflitos em ambiente escolar. Ciênc. cogn., Rio de Janeiro, 2011, dez, v. 16, n. 3, p. 151-166.

SCHWERTNER, S; ROVEDA, A; LOPES, M. Estratégias curriculares em espaços escolares. Pro-posições, 2016, Jan-abr., v. 27, n. 1 (79), p. 197-200.

SILVA, Eduardo P. (2011). Ética, loucura e normalização: diálogo entre a psicanálise e Michel Foucault. Psicologia Ciência e Profissão. Brasília, 2011, Dez, v.21, n. 4, p. 16-25.

SILVA, Nyrluce Marília Alves da; FREITAS, Alexandre Simão de. A ética do cuidado de si no campo pedagógico brasileiro: modos de uso, ressonâncias e desafios. Pro-Posições, 2015, Jan-abr., v. 26, n. 1 (76), p. 217-233. 